\title{
The Effect of Nickel Foam Current Collector in Carbon Electrode Based Electric Double Layer Capacitor
}

\author{
Jong H. KIM, Kyoung H. SHIN, Chang S. JiN, Dong K. KIM, Yong G. KIM, \\ Jong H. PARK, Yong S. LEE, Yong S. JOO, and Kyung H. LEE
}

\begin{abstract}
Energy Storage Research Center, Korea Institute of Energy Research (Dae-Duck Science Town, Taejon 305-343, Korea)
\end{abstract}

Received June 1, 2001 ; Accepted August 2, 2001

\begin{abstract}
Activated carbon (AC) powder as an active electrode material and open-pore nickel foam as a current collector material were used for an electric double layer capacitor (EDLC) with an aqueous electrolyte of KOH mixture. The electrochemical characteristics of the EDLC being made of $3 \mathrm{~cm}$ by $3 \mathrm{~cm}$ electrode size were investigated by chargedischarge cycle tests, impedance analyzer and cyclic voltametry measurements. As a current collector, nickel foam with concave surface and many open-pore showed larger specific capacitance and lower impedance than that of nickel foil with a flat surface. As results from experiments, much improved specific capacitance of about $300 \mathrm{~F} / \mathrm{g}$ at 40 $\mathrm{mA} / \mathrm{cm}^{2}$ of discharge current density and fairly low specific ESR of $0.63 \Omega \mathrm{cm}^{2}$ at $1 \mathrm{kHz}$ were obtained from the EDLC with the nickel foam current collector. The specific leakage current was measured as $0.18 \mathrm{~mA} / \mathrm{cm}^{2}$ with respect to the apparent electrode area of the EDLC with nickel foam current collector.
\end{abstract}

Key Words : Electric Double Layer Capacitor (EDLC), Activated Carbon (AC) Electrode Sheet, Nickel Foam Current Collector, Specific Capacitance, Impedance

\section{Introduction}

Based on the electric double layer theory, the EDLC stores electrostatic charges in a polarized liquid layer at the interface between an ionic conduction electrolyte and a conducting electrode. Thus, energy storage capacity increases by increasing the interface area. As an electrode material, activated carbons $(\mathrm{AC})$ are used in general due to its large specific surface area mainly obtained from micro- and meso-pores and also due to its high electrical conductivity. However, not all the specific surface area of $\mathrm{AC}$ is effective to store the charges because some pores are covered or filled by a binder material and surrounded by neighbors of $\mathrm{AC}$ particles. It is known that high value for the specific capacitance with respect to an active area of electrode materials is ranged between 15 to $30 \mu \mathrm{F} / \mathrm{cm}^{2}$ theoretically in electric double layer. ${ }^{1}$ )

On the other hand, not only the energy storage capacity (i.e., capacitance) but also internal resistance of the EDLC is an important parameter to characterize the EDLC because the internal resistance decides an energy transfer capability (i.e., power) of the EDLC in practical usage. In the electrode there are a large number of grain boundaries among AC particles. These boundaries cause the interfacial boundary resistance during charge transfer process, in other words, charge or discharge step for the EDLC. Therefore, for a thick electrode which a has longer path length of the charge transfer, the electrical resistance of the EDLC becomes higher than that of thinner one even though total capacitance gets increased. In the case of same thickness of electrode it is important to mix up with different sizes of $\mathrm{AC}$ particles optimally in order to increase parallel bonded grain boundaries so as to minimize the boundary resistance. In the referenced literature, ${ }^{2)}$ it is reported that a high filling density of $\mathrm{AC}$ with small particle size resulted in sheet-type electrodes with a very low sheet resistance and a high capacitance.

To reduce the contact resistance between the $\mathrm{AC}$ particles and the current collector surface it is necessary to increase the contact surface area. As the current collector a metal foil of being higher electrical conductivity and yielding material is widely used depending on electrolyte. As one of the metal current collectors, an open-pore nickel foam had been examined recently by a few researchers. By spraying a slurry state of activated carbon and binder mixture on the nickel foam had been tried. ${ }^{3)}$ And also, the nickel foam containing activated carbon particles as itself had been pressed to form a composite sheet of electrode and current collector. ${ }^{4)}$

In our work, authors had tried to find another method of which an $\mathrm{AC}$ sheet being mixed with binder was prepared and pressed on the nickel foam for the EDLC. Hereafter we would like to present some characteristics we investigated for our own EDLC.

\section{1 Preparation of the EDLC}

\section{Experimental}

Activated carbon (AC, Kansai Coke, Japan) powder being about $3000 \mathrm{~m}^{2} / \mathrm{g}$ of the specific surface area and $18 \AA$ of average pore diameter was used. The $\mathrm{AC}$ powder was mixed with suspending polytetrafluoroethylene (PTFE, Teflon 30, DuPont Co., USA) particles in isopropyl alcohol $(98 \%$, Junsei Chem. Co., Japan). A wire-bar-coater 
(Sheen Instrument Ltd., England) was used to form AC sheets about $250 \mu \mathrm{m}$ of thickness. After vaporization of isopropyl alcohol, the AC sheet was cut to be corresponding to a size of the EDLC electrode.

SEM photographs of the $\mathrm{AC}$ powder and the $\mathrm{AC}$ sheet were shown in Fig. 1(a) and (b). The AC powder itself was initially a mixture state of large particles (up to 20 $\mu \mathrm{m}$ diameter) and small particles (2-5 $\mu \mathrm{m}$ diameter). The shape and size of $\mathrm{AC}$ powder, however, were not changed after forming the $\mathrm{AC}$ sheet, as shown in Fig. 1(b). It looks that the dispersed PTFE aggregates sub-micron AC particles in the AC sheet.

A nickel foam (Eltech Co., USA) with $1.3 \mathrm{~mm}$ of thickness and $500 \mathrm{~g} / \mathrm{m}^{2}$ of a specific mass per unit area was used for the current collector. As shown in Fig. 2(a), the surface of the nickel foil is flat, while there are openpores in the nickel foam with about $500 \mu \mathrm{m}$ of diameter. Inside the open-pores, $100-200 \mu \mathrm{m}$ diameter of small holes connecting neighbor open-pores are evenly distributed. Considering nickel foil current collectors, it is notable that the contact area of the nickel foam with AC particle can be increased due to larger surface area of the nickel foam itself as shown in Fig. 2(b). Furthermore, by pressing the $\mathrm{AC}$ sheet on the foam, a tightness of physical adhesion between the nickel current collector and $\mathrm{AC}$ sheet can be improved.

In our work, the AC sheet and nickel foam current collector were pressed together so that the thickness of the
AC sheet above the pressed nickel foam was about 220 $\mu \mathrm{m}$. The pressed electrodes and current collector was dried at $120^{\circ} \mathrm{C}$ for $24 \mathrm{hrs}$. A unit cell of the EDLC was assembled by bipolar stacking with a polypropylene film (Celgard 3501) as a separator. Electrolyte of mixed $\mathrm{KOH}$ solution with $\mathrm{LiOH}$ and $\mathrm{NaOH}$ was used. Its total $\mathrm{OH}^{-}$ ion concentration was $7.5 \mathrm{M}$.

\section{2 Characteristic measurements}

Charge-Discharge Cycle Test:

Charge-discharge test of the prepared EDLC was carried out using a Capacitor Cycle Test System (Arbin MSP-2043, USA). Before the cycle test, over 20 cycles of initial cycle tests for training the EDLC was conducted. At the time of training the charge current density with respect to the apparent electrode area of $9 \mathrm{~cm}^{2}(3 \mathrm{~cm}$ by $3 \mathrm{~cm}$ size) was maintained as $1 \mathrm{~mA} / \mathrm{cm}^{2}$ and the voltage was varied from $0.01 \mathrm{~V}$ to $0.9 \mathrm{~V}$. In the charge-discharge test a test cycle program was set up with three steps as (i) charge up to $0.9 \mathrm{~V}$ with a constant current of $10 \mathrm{~mA}$. $\mathrm{cm}^{2}$, (ii) hold the constant voltage for $10 \mathrm{~min}$, (iii) and discharge to $0.01 \mathrm{~V}$ with the constant discharge current density of $5 \mathrm{~mA} / \mathrm{cm}^{2}$ to $40 \mathrm{~mA} / \mathrm{cm}^{2}$.

The capacitance of the EDLC was obtained from the discharging curve. The specific capacitance for the halfcell electrode, $\mathrm{F} / \mathrm{g}$, was calculated with respect to the half-cell electrode weight.

Impedance Test:

Voltage drop at the instant of initial discharge was (a)

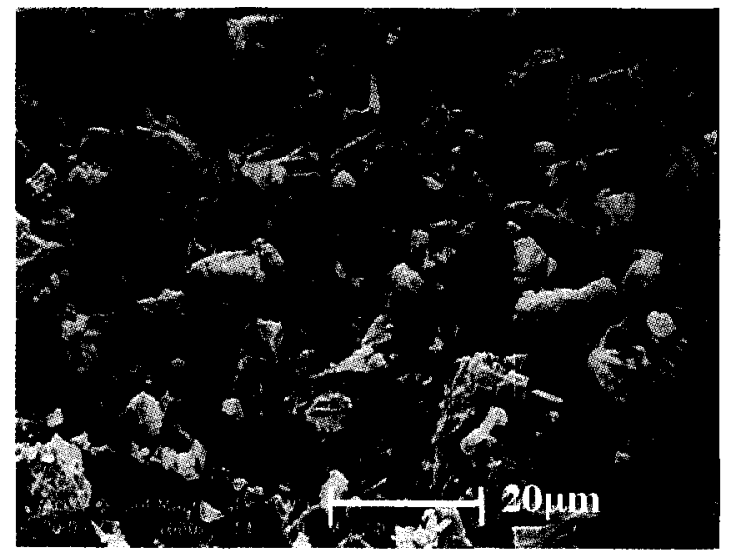

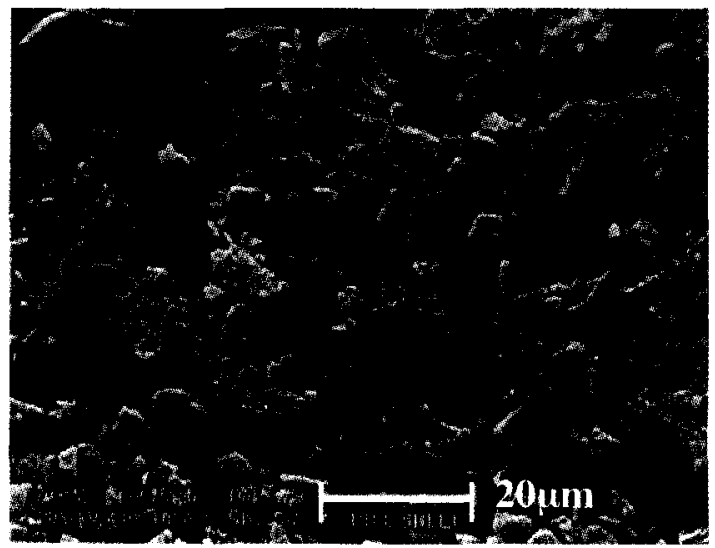

(b)

Fig. 1 SEM photographs of $\mathrm{AC}$ particles (a) and $\mathrm{AC}$ sheet (b).

(a)

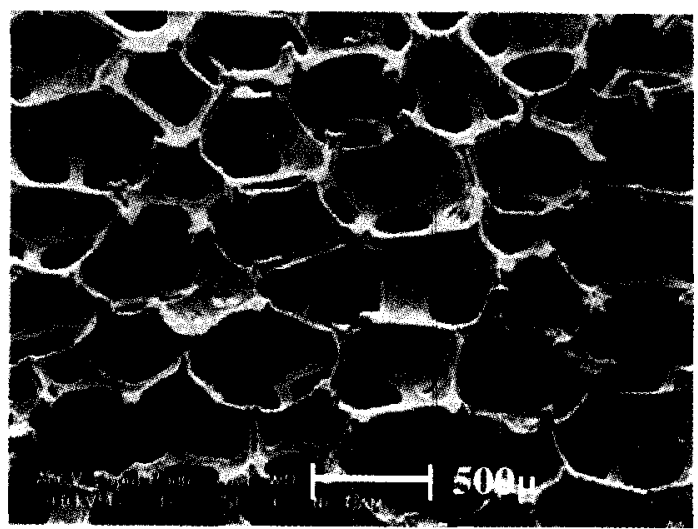

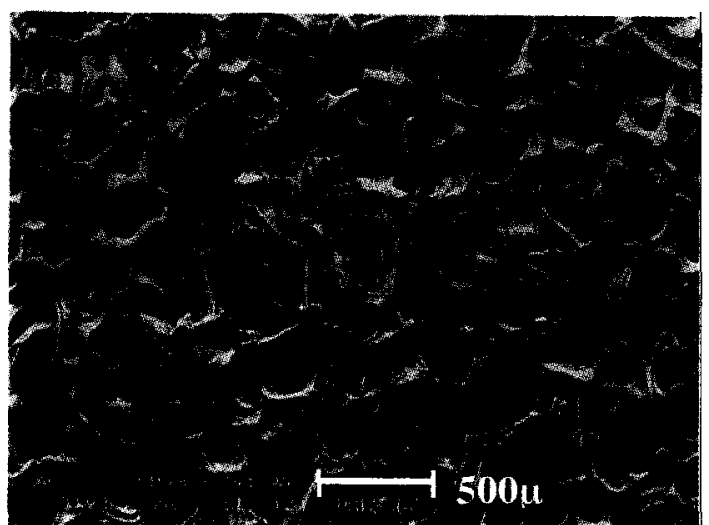

(b)

Fig. 2 SEM photographs of Ni foam (a) and Ni-foam pressed (b). 


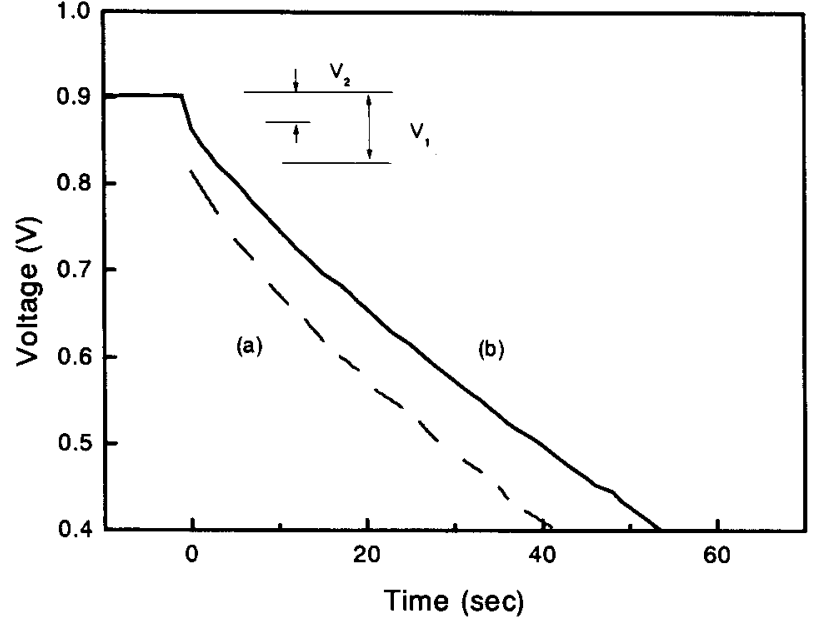

Fig. 3 Discharge curves of EDLC-Ni-foil (a) and EDLC-Nifoam (b) with constant discharge current density of 10 $\mathrm{mA} / \mathrm{cm}^{2}$.

measured from the discharge curve. Also, the AC impedance was measured by an Electrochemical Impedance Analyzer (Jahner Electrik IM6, Germany). Variations of $\mathrm{AC}$ impedance in the frequency range of $10^{-3}-10^{4} \mathrm{~Hz}$ were recorded.

Cyclic Voltammogram:

Cyclic voltamogram of the EDLC was recorded by a Potentio-Galvanostat (EG\&G $273 \mathrm{~A}$, USA) to confirm a double layer capacitance and its repetition stability. Voltage window was from $0 \mathrm{~V}$ to $1.0 \mathrm{~V}$ under the same sweep rate of $20 \mathrm{mV} / \mathrm{s}$.

Leakage Current and Self-Discharge Test:

The leakage current was obtained by measuring the current for 3 hrs of constant voltage charge condition at the voltage of $0.9 \mathrm{~V}$. The self-discharge voltage was measured by recording the voltage variation under opencircuit condition from working voltage of $0.9 \mathrm{~V}$ down to $80 \%$ of the working voltage. Initially, the working voltage was maintained for 30 minutes in the constant voltage charge step.

\section{Results and Discussion}

\section{1 Charge-discharge characteristics}

Figure 3 shows discharge curves of the EDLCs prepared by using Ni-foil and Ni-foam current collectors under a constant current condition of $10 \mathrm{~mA} / \mathrm{cm}^{2}$. Just after the initial stage of discharge the voltage decreases almost linearly on both capacitors.

IR drop of the EDLC at the initial stage during several milliseconds is known as its $\mathrm{DC}$ resistance caused by all kinds of electrical resistance inside the EDLC including a wiring resistance at lead terminal connection points. The considerably large IR drop about $90 \mathrm{mV}\left(V_{1}\right)$ was observed from the EDLC with Ni-foil, whereas about $30 \mathrm{mV}$ $\left(V_{2}\right)$ from the EDLC with Ni-foam. Since the contact area between nickel surface and $\mathrm{AC}$ particles is larger in the EDLC with Ni-foam than with Ni-foil as mentioned previously, its small IR drop is readily expected one. But for more detail investigation of resistance characteristics in the electrode, it is necessary to search for the AC imped-

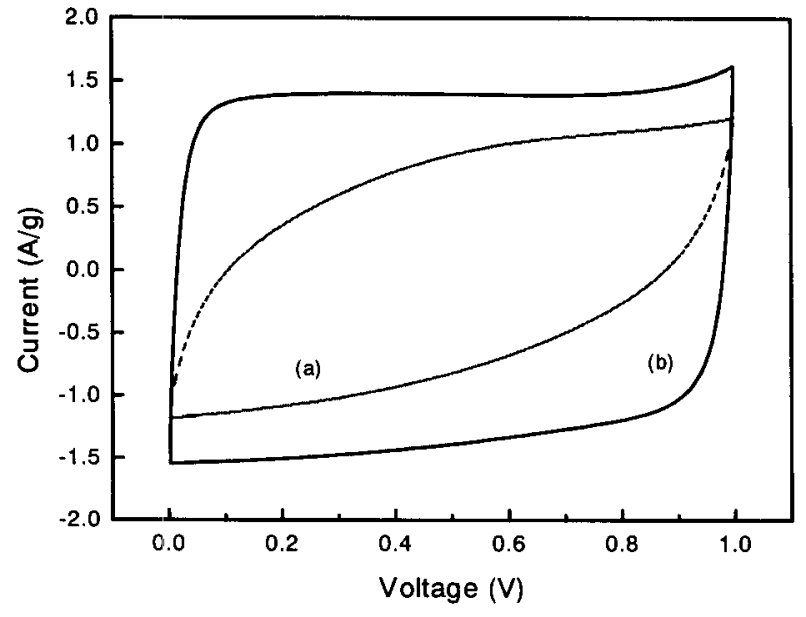

Fig. 4 Cyclic voltagrams of EDLC-Ni-foil (a) and EDLC-Nifoam (b) at scan rate of $20 \mathrm{mV} / \mathrm{s}$.

ance behavior as described next section in this paper.

Cyclic voltammogram is helpful to understand macroscopic electrochemical behavior of the EDLC during the charge and discharge processes. The cyclic voltammogram of an ideal EDLC must be a regular square shape, while that of the non-ideal EDLC becomes a parallelogram shape. Figure 4 shows cyclic voltammograms of the EDLC with Ni-foil and with Ni-foam. There are no current peaks caused by a redox for both EDLCs, especially up to $0.9 \mathrm{~V}$. But for the EDLC with Ni-foil the charge/discharge behavior is not so close to an ideal one, because the internal resistance of the EDLC with Ni-foil has comparatively higher. Also, it is notable that the EDLC with $\mathrm{Ni-foam} \mathrm{has} \mathrm{much} \mathrm{larger} \mathrm{area} \mathrm{enclosed} \mathrm{by}$ the curves of voltammogram than the EDLC with Ni-foil. The specific capacitances calculated from these curves are $271 \mathrm{~F} / \mathrm{g}$ and $152 \mathrm{~F} / \mathrm{g}$ for EDLCs with Ni-foam and $\mathrm{Ni}$-foil current collectors respectively. However, the specific capacitance obtained from the cyclic voltammogram does not mean a representative capacitance value. The energy stored during the charge process in the cyclic voltammogram test may not be enough to make a fully charged state of the EDLCs. To make a fully charged state, as in the charge-discharge cycle test, we usually have to set a constant voltage charge process just after reaching to a given charge voltage. In the cyclic voltammogram test, there is no constant voltage charge process so that the energy supplied to a EDLC may not be enough to fulfill an actual capacitance depends on the sweep rate, especially, at higher sweep rate.

\section{2 Impedance characteristics}

In the Fig. 5 of a Nyquist plot, $\mathrm{AC}$ impedances in the frequency range from $10^{-3}$ to $10^{4} \mathrm{~Hz}$ for the EDLCs with $\mathrm{Ni}$-foil and Ni-foam were plotted respectively. As mentioned about IR drop previously, the EDLC with Ni-foam shows lower impedance of $R_{\text {real }}$ at $R_{\text {imag }}=0$. At $1 \mathrm{kHz}$ of the frequency the specific ESR was measured as about $0.63 \Omega \mathrm{cm}^{2}$ (i.e., $0.07 \Omega$ for $9 \mathrm{~cm}^{2}$ of the apparent electrode area). Also, the slop of impedance variation curve at low frequency region is much close to an ideal EDLC, that is, the phase angle of $\tan \left(R_{\text {imag. }} / R_{\text {real }}\right)$ at low frequency re- 


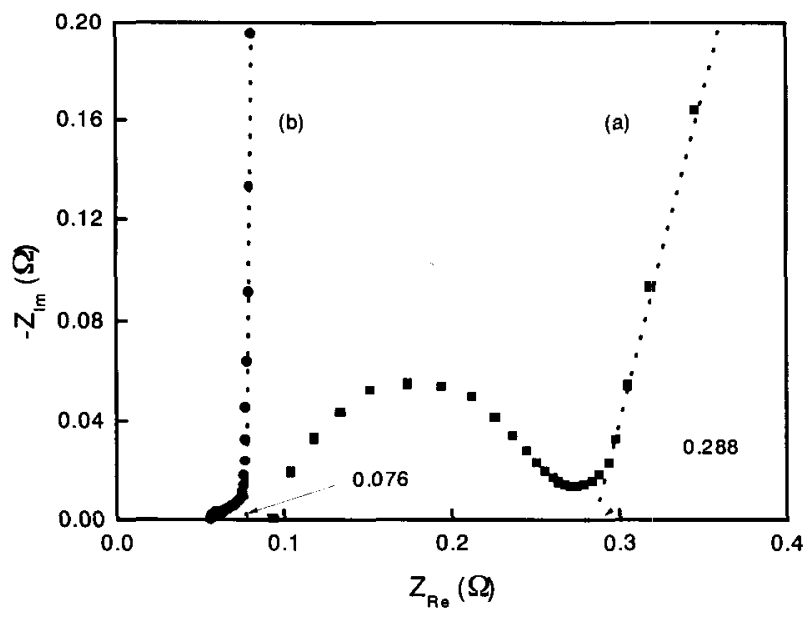

Fig. 5 Nyquist plot of EDLC-Ni-foil (a) and EDLC-Ni-foam (b).

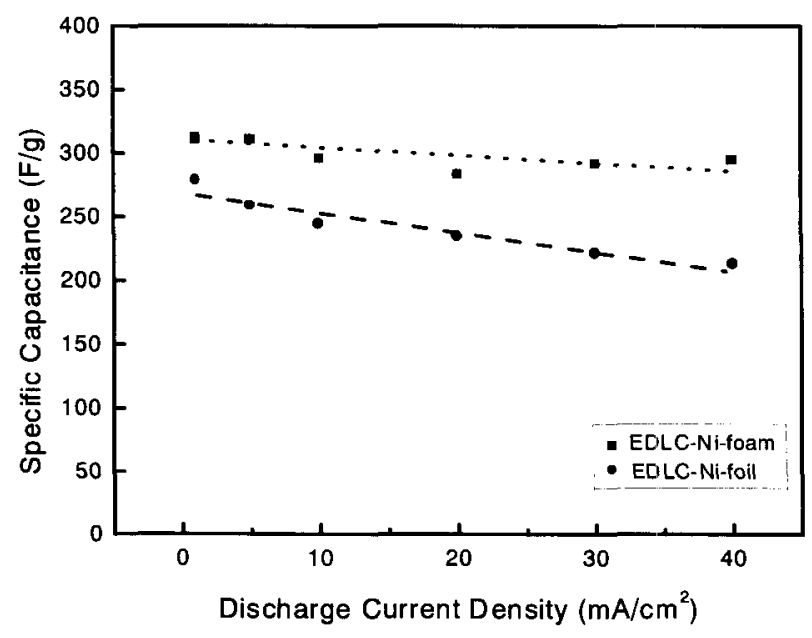

Fig. 6 Variation of the specific capacitance of EDLC at different discharge current densities.

gion is nearly $90 \mathrm{deg}$. In the mean time the EDLC with Ni-foil shows higher impedance and the slop at low frequency region is less steep. Furthermore, in the high frequency region, there is a semi-circle indicating a Faradaic reaction occurrance.

From this figure it is able to understand that a pore distribution in the electrode of the EDLC with Ni-foam has more favorable and the interfacial resistance among $\mathrm{AC}$ particles in the electrode is desirably reduced. Also, even at higher frequency region, a Faradaic reaction does not occur.

\section{3 Specific capacitance variations}

As shown in the Fig. 6, variations of the specific capacitance (capacitance per unit weight of half cell electrode, F/g) which were obtained from the chargedischarge tests were plotted against different discharge current densities for both EDLC with Ni-foil and Ni-foam respectively. The EDLC with $\mathrm{Ni}$-foam shows higher specific capacitance than the EDLC with $\mathrm{Ni}$-foil in all cases of discharge current densities tested. The EDLC with $\mathrm{Ni}$ foam does not show a deterioration trend of the specific capacitance maintaining around $300 \mathrm{~F} / \mathrm{g}$ even at higher discharge current density up to $40 \mathrm{~mA} / \mathrm{cm}^{2}$. This means

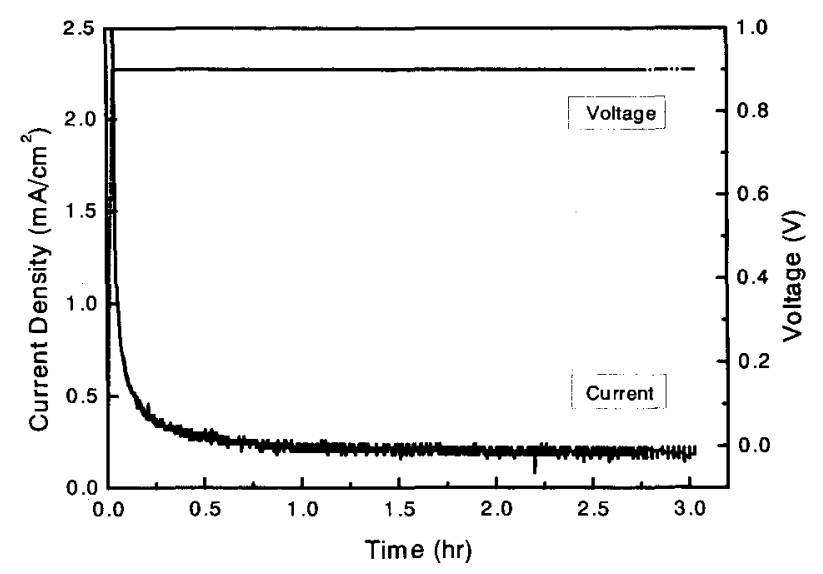

Fig. 7 Leakage current of EDLC-Ni-foam.

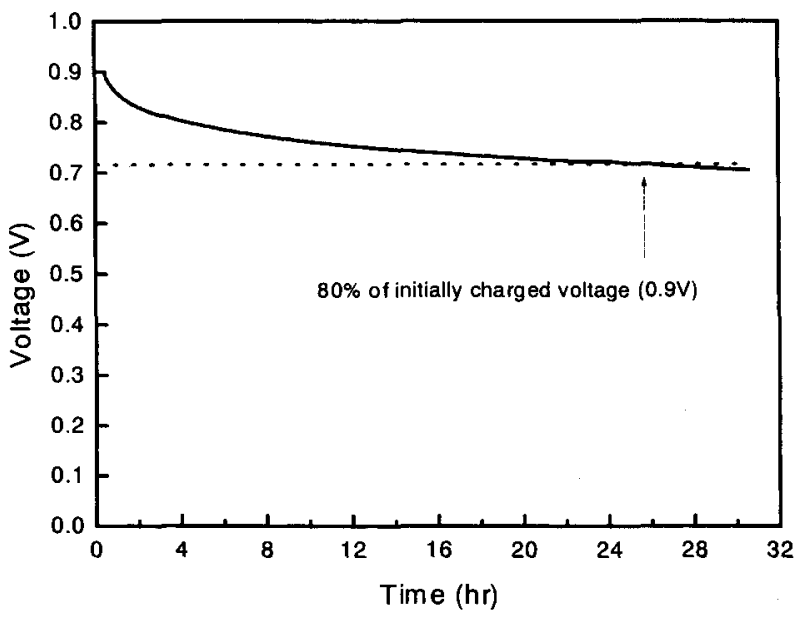

Fig. 8 Voltage variation by self-discharge of EDLC-Ni-foam.

that the specific capacitance with respect to the active surface area of AC with $3000 \mathrm{~m}^{2} / \mathrm{g}$ used in this study becomes $10 \mu \mathrm{F} / \mathrm{cm}^{2}$. However, the specific capacitance of the EDLC with $\mathrm{Ni}$-foil has a deterioration trend. Its specific capacitance reduced from $258 \mathrm{~F} / \mathrm{g}$ at $5 \mathrm{~mA} / \mathrm{cm}^{2}$ to $213 \mathrm{~F} / \mathrm{g}$ at $40 \mathrm{~mA} / \mathrm{cm}^{2}$.

As mentioned previously the specific capacitances obtained from the charge-discharge tests have shown much higher values than those from the cyclic voltammogram since the EDLCs were fully charged during the constant voltage charge process for 10 minutes.

\section{4 Leakage current and self-discharge}

Figure 7 shows the current variation under the constant voltage charge condition at working voltage of $0.9 \mathrm{~V}$. Even though the charge voltage of the EDLC with Ni-foam current collector was speedily reached at the working voltage of $0.9 \mathrm{~V}$ according to the charge current density of $10 \mathrm{~mA} / \mathrm{cm}^{2}$, the EDLC was not fully charged until the charge current maintains a constant value as a leakage current value. As shown in the Fig. 7, the current within 2000 seconds includes both leakage current and charge current. But, as the time goes on after 2000 seconds, the portion of charge current diminishes and the leakage current converses as a nearly constant value of $0.18 \mathrm{~mA} / \mathrm{cm}^{2}$ (i.e., $1.62 \mathrm{~mA}$ for $9 \mathrm{~cm}^{2}$ of the EDLC's apparent electrode area. 
As described in the battery test method of the USABC Code, the self-discharge voltage was measured by means of an open circuit test without discharge current. As shown in the Fig. 8, it takes for about 24 hrs to be lower down to $80 \%$ of initially charged voltage by the selfdischarge. After $24 \mathrm{hrs}$ of self-discharge time, the selfdischarge rate shows a less steep trend.

\section{Conclusions}

The result from experimental measurements for the EDLC made of activated carbon electrode and nickel foam current collector shows quite improved specific capacitance about $300 \mathrm{~F} / \mathrm{g}$ at $40 \mathrm{~mA} / \mathrm{cm}^{2}$ which is corresponding to the specific capacitance of $10 \mu \mathrm{F} / \mathrm{cm}^{2}$ with respect to the active surface area of activated carbon used. And also, it shows fairly low specific ESR of 0.63 $\Omega \mathrm{cm}^{2}$ at $1 \mathrm{kHz}$. The specific leakage current was measured as $0.18 \mathrm{~mA} / \mathrm{cm}^{2}$ with respect to the apparent elec- trode area. It takes for about 24 hrs to be lower down to $80 \%$ of initially charged voltage by the self-discharge. After $24 \mathrm{hrs}$ of self-discharge time, the self-discharge rate shows a less steep trend.

\section{Acknowledgements}

This study was conducted as a research work of National Research Lab Program supported by Korean Ministry of Science and Technology.

\section{References}

1) A. Burke, J. Power Sources, 91, 37 (2000).

2) A. Yoshida, S. Nonaka, I. Aoki, and A. Nishino, J. Power Sources, 60, 213 (1996).

3) L. Bonnefoi, P. Simon, J. F. Fauvarque, C. Sarrazin, and A. Dugast, J. Power Sources, 79, 37 (1999).

4) I. Bispo-Fonseca, J. Aggar, C. Sarrazin, P. Simon, and J. F. Fauvarque, J. Power Sources, 79, 238 (1999). 